\title{
Treatment of velopharyngeal insufficiency by autologous fat injection
}

\author{
Igor Leuchter • Valérie Schweizer • \\ Judith Hohlfeld · Philippe Pasche
}

Received: 4 July 2009 / Accepted: 5 November 2009 / Published online: 23 December 2009

(C) Springer-Verlag 2009

\begin{abstract}
Velopharyngeal insufficiency (VPI) is a structural or functional trouble, which causes hypernasal speech. Velopharyngeal flaps, speech therapy and augmentation pharyngoplasty, using different implants, have all been used to address this trouble. We hereby present our results following rhinopharyngeal autologous fat injection in 18 patients with mild velopharyngeal insufficiency (12 soft palate clefts, 4 functional VPI, 2 myopathy). 28 injections were carried out between 2004 and 2007. The degree of hypernasal speech was evaluated pre- and postoperatively by a speech therapist and an ENT specialist and quantified by an acoustic nasometry (Kay Elemetrics ${ }^{\mathrm{TM}}$ ). All patients were exhaustively treated with preoperative speech therapy (average, 8 years). The mean value of the nasalance score was $37 \%$ preoperatively and $23 \%$ postoperatively $(p=0.015)$. The hypernasality was reduced postoperatively in all patients (1-3 degrees of the Borel-Maisonny score). There were no major complications, two minor complications (one hematoma, one cervical pain). The autologous fat injection is a simple, safe, minimally invasive procedure. It
\end{abstract}

I. Leuchter · V. Schweizer · P. Pasche

Department of Otolaryngology,

University Hospital Centre of the Canton of Vaud (CHUV), 1011 Lausanne, Switzerland

J. Hohlfeld

Department of Paediatric Surgery,

University Hospital Centre of the Canton of Vaud (CHUV), 1011 Lausanne, Switzerland

I. Leuchter $(\square)$

Service ORL et Chirurgie Cervico-Faciale,

Hôpitaux Universitaires de Genève,

Rue Gabrielle-Perret-Gentil 4, 1211 Geneva 14, Switzerland

e-mail: igor.leuchter@hcuge.ch proves to be efficient in cases of mild velopharyngeal insufficiency or after a suboptimal velopharyngoplasty.

Keywords Velopharyngeal insufficiency .

Autologous fat $\cdot$ Velopharyngoplasty .

Velo-cardio-facial syndrome

\section{Introduction}

Velopharyngeal closure is the result of the combined action of the velar and pharyngeal muscles. Velopharyngeal insufficiency (VPI) results in hypernasal speech and occasionally in nasal regurgitation. This condition is most commonly the consequence of an anatomic abnormality: cleft palate, submucous clefts, congenital short soft palate and defects linked to over 400 recognized syndromes, with velocardiofacial (VCF) being the most common [1]. Iatrogenic causes are also common with an important incidence of VPI after adenoidectomy or uvulopharyngopalatoplasty (UPPP) in patients with occult submucous cleft palate or a short velum. In most cases, VPI may be compensated by reinforcement of the medial (Passavant's pad) and lateral pharyngeal wall by speech therapy and/or by the presence of adenoid rests. A velopharyngoplasty is indicated when the velar and pharyngeal contractions are deficient and the velopharyngeal space too large. In cases of minor VPI with preserved velar motion, or after insufficient results of a velopharyngoplasty, an augmentation of the posterior pharyngeal wall can be proposed. Since the first description of the augmentation pharyngoplasty with Vaseline in 1900 by Gersuny [2], a large sample of different materials has been used: paraffin [3], teflon [4-6], silicone [7], collagen [8], autologous cartilage [9], mucosal and muscle flaps [10, 11]. In 1926, von Gaza [12] described the first autologous fat 
implantation in the posterior wall of the rhinopharynx using an external cervical approach. In 2001, Dejonckere et al. [13] injected autologous fat transorally in 17 patients with mild VPI with good results in terms of nasality and patient satisfaction with an average follow-up of 9 months. We present our results of 28 autologous fat injections in the posterior pharyngeal wall in 18 patients with speech and acoustic nasometric long-term results.

\section{Materials and methods}

Patients: inclusion criteria

Eighteen patients were included in the study (13 female and 5 male), mainly adolescents, ages 8-53 years (average 19.6 years). All patients had a consistent hypernasal voice during conversational speech as evaluated by an experienced team composed of a phoniatrician and a speech therapist. Patients were operated and followed in a single institution (Department of Otolaryngology, Head and Neck Surgery, University Hospital of Lausanne), between May 2004 and May 2008. Our inclusion criteria were (1) moderate hypernasal speech without major articulatory VPIrelated troubles; (2) visible velar mobility allowing a velo- pharyngeal closure of at least $50 \%$, evaluated by nasofibroscopy; (3) extensive speech therapy. Exclusion criteria included contraindication for general anesthesia and severe articulatory or language acquisition delay. The etiology of the VPI was a short palate after correction of a cleft palate for 12 patients, a short soft palate for 4 patients, and myopathy (myotonic dystrophy and chronic progressive external ophthalmoplegia) for 2 other patients. Three patients were known to have a VCF syndrome with cleft palate and facial malformation. Six patients had been treated previously by a velopharyngoplasty but still demonstrated nasal air emission during phonation. One patient had a previous retropharyngeal autologous fat injection in another center with inadequate results. All patients were extensively treated with preoperative speech therapy (average 8 years). Patients' details are summarized in Table 1.

Pre and postoperative evaluations

The pre and postoperative assessments included: clinical examination of the voice; nasofibroscopy and instrumental evaluation of the rhinolalia. The perceptual evaluation of the voice was judged by a speech pathologist and a phoniatrician using spontaneous speech, a short phonetically equilibrated text with nasal and denasal phonemes

Table 1 Description of patients

\begin{tabular}{|c|c|c|c|c|c|c|c|c|c|c|}
\hline Patient & Sex & Age & Cause of VPI & $\begin{array}{l}\text { Previous } \\
\text { VPP }\end{array}$ & No injections & $\begin{array}{l}\text { Follow-up } \\
\text { (months) }\end{array}$ & $\begin{array}{l}\text { BM } \\
\text { preop }\end{array}$ & $\begin{array}{l}\text { BM } \\
\text { postop }\end{array}$ & $\begin{array}{l}\text { Nasalance } \\
\text { preop }(\%)\end{array}$ & $\begin{array}{l}\text { Nasalance } \\
\text { postop (\%) }\end{array}$ \\
\hline 1 & $\mathrm{~F}$ & 10 & $\mathrm{CP}$ & + & 2 & 11 & $2 \mathrm{~m}$ & $2 b$ & 61 & 50 \\
\hline 2 & $\mathrm{~F}$ & 12 & $\mathrm{CP}$ & + & 3 & 19 & 2 & $2 / 1$ & 34 & 29 \\
\hline 3 & $\mathrm{~F}$ & 21 & SP & & 3 & 22 & 2 & $2 / 1$ & 50 & 24 \\
\hline 4 & $\mathrm{~F}$ & 11 & CLP/22q11 & & 2 & 12 & $2 / 1$ & $1 / 2$ & 17 & 7 \\
\hline 5 & $\mathrm{~F}$ & 16 & $\mathrm{CP}$ & & 1 & 2 & $2 / 1$ & $2 / 1$ & 25 & 29 \\
\hline 6 & $\mathrm{~F}$ & 15 & CLP & & 2 & 20 & $2 b$ & 1 & 16 & 5 \\
\hline 7 & $\mathrm{~F}$ & 53 & MP & & 1 & 6 & 2 & $1 / 2$ & 63 & 25 \\
\hline 8 & M & 11 & $\mathrm{CP}$ & & 2 & 12 & $2 \mathrm{~m}$ & $1 / 2$ & 40 & 20 \\
\hline 9 & $\mathrm{~F}$ & 34 & CLP & & 2 & 20 & $2 / 1$ & $1 / 2$ & 54 & 39 \\
\hline 10 & M & 18 & $\mathrm{CP}$ & + & 1 & 5 & $2 \mathrm{~m}$ & $2 b$ & 33 & 28 \\
\hline 11 & $\mathrm{~F}$ & 13 & $\mathrm{SP}$ & + & 1 & 8 & $2 b$ & $1 / 2$ & 30 & 12 \\
\hline 12 & M & 13 & $\mathrm{CP} / 22 \mathrm{q} 11$ & + & 1 & 5 & $2 / 1$ & $1 / 2$ & 37 & 21 \\
\hline 13 & $\mathrm{~F}$ & 33 & $\mathrm{SP}$ & + & 2 & 6 & $2 b$ & 1 & 28 & 11 \\
\hline 14 & $\mathrm{M}$ & 8 & $\mathrm{SP}$ & & 1 & 10 & $2 / 1$ & 1 & 19 & 8 \\
\hline 15 & $\mathrm{~F}$ & 12 & $\mathrm{CP}$ & & 1 & 8 & $2 / 1$ & $1 / 2$ & 31 & 10 \\
\hline 16 & $\mathrm{~F}$ & 43 & MP & & 1 & 7 & $2 \mathrm{~b}$ & $2 b$ & 63 & 59 \\
\hline 17 & $\mathrm{~F}$ & 13 & $\mathrm{CP}$ & & 1 & 6 & $2 / 1$ & $1 / 2$ & 19 & 20 \\
\hline 18 & M & 17 & $\mathrm{CP} / 22 \mathrm{q} 11$ & & 1 & 10 & $2 b$ & $2 / 1$ & 44 & 23 \\
\hline Mean & & 19.6 & & & 1.6 & 10.5 & & & 37 & 23 \\
\hline Total & $13 \mathrm{~F} / 5 \mathrm{M}$ & & & & 28 & & & & & \\
\hline
\end{tabular}

$\overline{F \text { Female, } M \text { male, } C P \text { cleft palate), } C L P \text { cleft labial palate, } S P \text { congenital short soft palate, } M P \text { myopathy), } V P P \text { velopharyngoplasty, } A g e \text { age at }}$ the first injection, $B M$ Borel-Maisonny score, Follow-up interval in months between the preoperative evaluation and the last intervention, $22 q 11$ velo-cardio-facial syndrome 
read orally, and maximum phonation time. In an attempt to limit interjudge variability, the perceptive scores were rated in consortium. The hypernasality was evaluated with the Borel-Maisonny score, based on the audible nasal emission, intelligibility and compensatory articulation during phonation (Table 2) [14]. Patients with severe articulation disorders (Borel-Maisonny score 3) were not included because the abnormal compensatory articulation with loss of intelligibility supplants the audible nasal air emission in the social discomfort and because these articulatory disorders could affect our clinical evaluation. The nasofibroscopy (Rhino-Laryngo Fibrescope ENF-GP, Olympus (C), Japan) was performed under local anesthesia. The patient was asked to produce the phonemes $/ \mathrm{a} /$, /i/, and $/ \mathrm{s} /$, which enabled evaluation of velar mobility and the degree of velopharyngeal closure. We evaluated the presence of a submucosal cleft, adenoid rests, and compensatory signs (Passavant's pad, lateral pharyngeal wall contraction). Special attention was given to identify an eventual ectopic carotid with an aberrant course in the rhinopharynx. The objective, quantitative assessment of nasalance was obtained using a KayPENTAX Model 6200 Nasometer. This technique consists of registering and filtering separately the acoustic energy emanating from the nose and the mouth with a microphone. The computer expresses a ratio of the nasal to nasal-plus-oral acoustic energy as a percentage called, nasalance [15]. The average nasalance value in normal French speech is defined as less than $30 \%$ for oral phonemes. A routine assessment of nasalance was made using the vowels /a/, /o/, /i/, four short French sentences without nasal phonemes and a short French text of about 30 -s reading time that contained no nasals. Each patient was evaluated preoperatively and postoperatively at 2 weeks, 2 months, 6 months, and every year postoperatively. The decision for a recurrent fat injection was made at the second postoperative evaluation (about 2 months after the intervention). This decision was based first on the wishes and satisfaction of the patient, then on the perceptual evaluation of nasality and on the nasofibroscopic evaluation of the fat pad in the rhinopharynx.

\section{Surgical procedure}

The procedures were executed under general anesthesia. The ventilation tube passed through the mouth. The site of fat harvesting was sterilely prepared ( 21 patients from the medial knee, 4 patients from the flank, 3 patients from the abdominal wall). A 2-mm skin incision was achieved without prior subcutaneous injection. When the patients had undergone a previous lipoaspiration, we chose the opposite leg or side of the abdomen. A 3-mm Coleman lipoaspiration canula connected to a $10-\mathrm{ml}$ sterilized Luer-lock syringe was introduced and about $15 \mathrm{ml}$ of fat tissue was
Table 2 Borel-Maisonny Score [14]: subjective evaluation of the hypernasality

\begin{tabular}{|c|c|}
\hline Type 0 & No phonation \\
\hline Type 1 & Excellent phonation, no nasal air emission \\
\hline Type $1 / 2$ & $\begin{array}{l}\text { Good phonation, intermittent nasal air emission, } \\
\text { good intelligibility }\end{array}$ \\
\hline Type $2 / 1$ & Phonation with partially corrected nasal air emission \\
\hline Type $2 b$ & $\begin{array}{l}\text { Phonation with continuous nasal emission } \\
\text { but good intelligibility and no social discomfort }\end{array}$ \\
\hline Type $2 \mathrm{~m}$ & $\begin{array}{l}\text { Phonation with continuous nasal emission, } \\
\text { poor intelligibility }\end{array}$ \\
\hline Type $2 / 3$ & $\begin{array}{l}\text { Phonation with continuous nasal emission } \\
\text { with compensatory articulation, poor intelligibility }\end{array}$ \\
\hline Type 3 & $\begin{array}{l}\text { Continuous compensatory articulation, } \\
\text { bad intelligibility }\end{array}$ \\
\hline
\end{tabular}

gently aspirated under negative pressure according to the Coleman technique [16]. The syringe with aspirated fat was then placed in a sterilized sleeve in a centrifuge and spun at $3,000 \mathrm{rpm}$ for $3 \mathrm{~min}$ to separate the aspirate from the nonviable components. The usable fat tissue, about $12 \mathrm{ml}$, was isolated and prepared in a 1-ml sterilized Luer-lock syringe. The pharynx was exposed such as in the classical tonsillectomy procedure with the tongue and the ventilation tube reclined with an orthostatic spatula (Fig. 1). A pediatric fiberbronchoscope (BF-MP60, Olympus (C) was introduced through the choana and the velum retraced upwards enabling good visibility of the rhinopharynx. The prepared fat was then injected intraorally in the submucosa of the rhinopharynx with a slightly curved-in 20-gauge canula. The main injection site was median at the point of velopharyngeal closure during phonation. Several paramedian injections were necessary to achieve a good pad of fat such that a "neo-Passavant's pad" was formed. The aim was to narrow the nasopharyngeal passage optimally. We intentionally avoided injecting too deeply forcing contact with the vertebral ligament or too laterally in contact with the tubar fossae. The postoperative course was simple: the patients were able to speak and swallow as soon as they recovered from the general anesthesia and were discharged the same day. The patients received a prescription for a 5day prophylactic antibiotherapy (amoxicillin/clavulanic acid, $3 \times 625 \mathrm{mg}, 500 / 125$ per day. The Student's $t$ test was used (with $p<0.001$ considered as significant) to compare nasalance improvement pre and postoperatively, using SPSS Statistics ${ }^{\circledR}$ 17.0.

\section{Results}

Twenty-eight fat injections were performed in the 18 patients, which represented a mean of 1.6 interventions per 


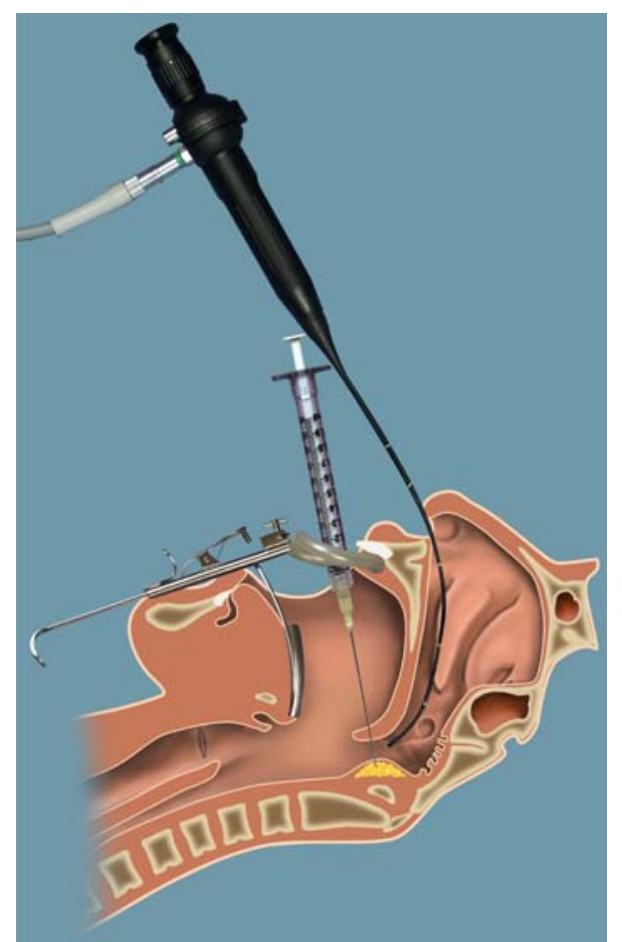

Fig. 1 Injection of autologous fat tissue in the submucosa of the posterior wall of the rhinopharynx under fibroscopic visualization. The site of injection in the rhinopharynx is accessed intraorally

patient. The average interval between each surgical procedure was 6.1 months. The average clinical follow-up period was 10.5 months (5-22 months) between the preoperative and the last postoperative assessment. The medial knee was chosen as the site of fat harvesting in most cases (21/28), essentially for aesthetic and ease of access reasons. The average volume of autologous injected fat was $11 \mathrm{ml}$. All patients were asked about immediate and delayed postoperative complications (hematoma, fever, infections) and pain. Most patients described immediate postoperative discomfort or mild pain in the nape of the neck, which disappeared the day after the intervention. One patient (No. 7) complained of pain in the region of the nape of the neck up to 3 weeks after the procedure. The localization of the pain could be explained by the operative position with hyperextension of the head and probably also by irritation of the vertebral ligament caused by the injections. One patient (No. 10) presented a postoperative hematoma of the medial knee, which did not necessitate any treatment. There were no complaints concerning the scar from the fat-harvesting incision. There were no major complications (e.g., bleeding, infections, and embolism). The perceptual nasality results (Borel-Maisonny score) are presented in Fig. 2 with the pre and postoperative scores (after the last injection). The nasality was significantly improved in all patients except Patient No. $16(p<0.001)$. Eleven patients had good postoperative phonation and three patients had entirely

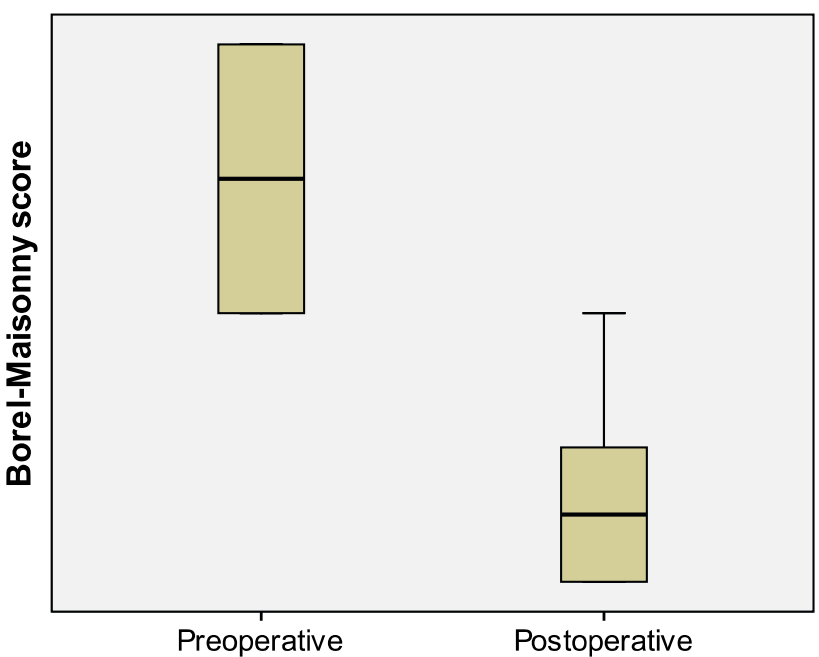

Fig. 2 The perceptive nasality results according to (the) Borel-Maisonny score (Table 2). Postoperative scores are quoted after the last injection

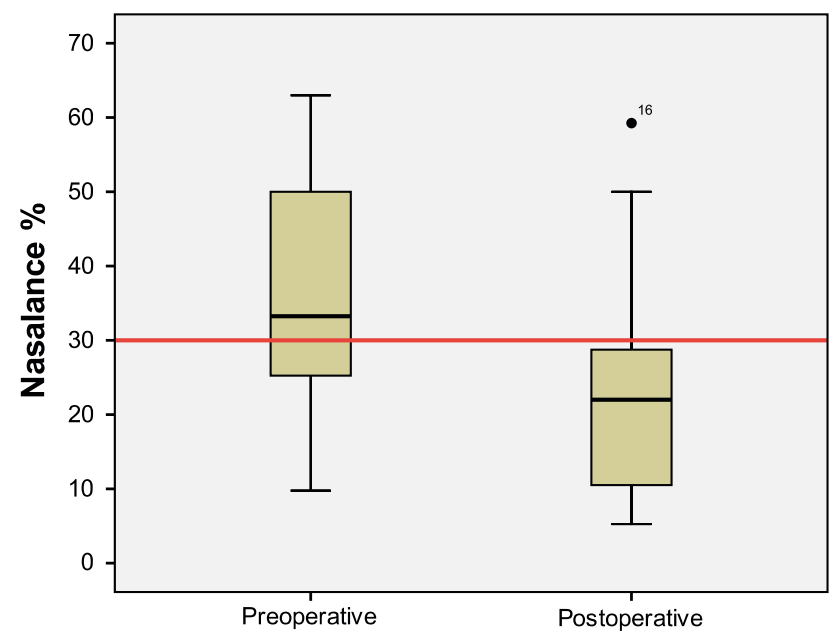

Fig. 3 The pre and postoperative nasalance results measured by Nasometry (KayPENTAX ${ }^{\mathrm{TM}}$ ). Normal nasalance is defined as less than or equal to $30 \%$ for oral phonemes

overcome their hypernasality. All patients had good intelligibility postoperatively. The objective quantitative results are presented in Fig. 3. The mean preoperative nasalance score was 36.5 and $23.3 \%$ postoperatively, after the last injection. The nasalance was significantly improved in all but two patients (Patients No. 5 and No. 16) $(p<0.001)$.

The criteria for a successful outcome were the satisfaction of the patient and the reduction of the nasal air emission observed subjectively (Borel-Maisonny score) and objectively (Nasometry). The necessity of recurrent intervention was caused by significant fat resorption causing a reoccurrence of the hypernasal speech. Subjectively, all patients but one (Patient No. 16) declared that they were satisfied. 
The injected fat into the submucosa of the rhinopharynx remained stable. No fat tissue migration was observed. An early resorption, between 30 and 50\%, estimated with nasofibroscopy, was observed at the first postoperative evaluation (2 months). At the following postoperative assessments, the fat pad appeared to be persistent and stable. A fat pad was present and still visible up to 22 months after the injection in one patient. Similarly, the functional postoperative results were stable after the first 2-month period of resorption.

\section{Discussion}

The goals of VPI treatment are to restore adequate function of the velopharyngeal sphincter, thereby diminishing nasal air emission during phonation, and to improve a patient's ability to communicate. In case of mild VPI, speech therapy plays an essential role but may be insufficient if an anatomic defect exists. Injections of different substances in the posterior pharyngeal wall to reduce the velopharyngeal space have been described in the literature for about 100 years. Soft tissue augmentation with an injected filler has been widely used by laryngologists for vocal fold medialization. Alloplastic materials are generally well tolerated but may evoke a foreign-body giant cell reaction (polydimethylsiloxane [17], teflon [18]), delayed hypersensitivity (collagen [19]) and injectate migration (teflon [20]). Cartilage and mucosal flaps have the advantage of avoiding these reactions, but the graft harvesting may increase patient's morbidity. Autologous fat as a soft substance is often considered as an ideal filler. Furthermore, it appears to be safe, nonimmunogenic, inexpensive, and is readily obtainable with low donor site morbidity [21]. For all these reasons, autologous fat transplantation has been broadly used for soft tissue augmentation by plastic surgeons and otolaryngologists for more than 100 years [22]. The major disadvantage of autologous fat is that initial augmentation may diminish rapidly due to fat resorption. This resorption results from the necrosis of fat at the time of transfer and gradual resorption of successfully transferred fat [23]. Different modifications of the original techniques to address fat viability have been described during the last decades. The modifications essentially concern the donor site, the aspiration methods, and the preparation and injection methods [24]. Despite the number of reports describing different harvest sites, there is no evidence of a preferred donor site for fat viability [25]. The abdominal wall, flank and medial knee are the most common donor sites, essentially because of the ease of access and aesthetics. Concerning the aspiration methods, conventional liposuction using a high negative vacuum extraction technique have been reported to damage up to $90 \%$ of the lipocytes [26]. Coleman proposed limiting the vacuum to the minimal negative pressure, manually withdrawing with a $10-\mathrm{ml}$ syringe attached to a $3-\mathrm{mm}$ two-holed blunt canula in a gradual manner [16]. Others have proposed a minimally traumatic technique, by which the fat tissue is drilled out through a sharp 4.5-mm canula [27]. Animal studies have suggested that direct excision allows increased graft survival rates compared to lipoaspiration [28, 29]. However, fat aspiration using the Coleman technique is the most popular method, as reported in the literature. The preparation of the harvested fat is one of the most essential conditions in terms of viability. Coleman emphasized the importance of removing the nonviable components of the aspirate (oil from ruptured lipocytes and blood) by centrifugation at 3,000 rpm for $3 \mathrm{~min}$ to isolate the viable lipocytes [16]. This technique has been widely accepted and has widespread use. Marques et al. [29] found a significantly better survival rate by washing the aspirated fat with Ringer's solution. The washing is suggested to eliminate inflammatory mediators and decrease resorption at the host site. Another method for improving fat survival and enhancing cell growth is the addition of growth factors [30]. Many authors report not adding growth factors because there are risks of chemical and mechanical damage to the delicate fat tissue [16], and there is little clinical evidence for use of such measures [24]. The site of injection is particularly important knowing that fat graft survival is principally based on the proximity to a blood supply. A distance of $2 \mathrm{~mm}$ from an arterial supply seems to be essential for fat graft survival; beyond this distance the fat tissue will necrose and fibrose [31]. There is a lack of accurate results concerning the fat graft survival in humans. Animal studies have demonstrated survival depending on the transfer site with the best longevity being when it is into the subcutaneous tissue [32]. Most clinical studies are based on subjective evaluations. Har-Shai et al. [33] report a fat graft survival rate up to $90 \%$ at 24 months using an integrated approach, and a pessimistic survival rate of $25 \%$ after 8 months [34]. We observed fat resorption between 30 and $50 \%$ at 2 months. The complications are rare and are the same in other surgical procedures: infections, local bleeding. Complications associated with the incision and harvesting (scars, bleeding) are rare. More dramatic complications concerning facial injections, such as fat emboli in the retinal and cerebral arteries, have been reported sparsely in the literature [35].

In searching for the ideal filler, the choice of autologous fat must be balanced with the necessity of eventual re-interventions. However, a certain quantity of fat resorption represents the advantage of avoiding an over-correction of the VPI, resulting in potential nasal obstruction, snoring and discomfort. Furthermore, our patient group is young (average 19.6 years), and the long-term morbidity (inflammation, infection, migration, extrusion carcinogenicity) of 
most alloplastic materials is still unpredictable. For all these reasons, we chose autologous fat as the injection material for our patients.

The most important condition for a satisfactory result after autologous fat injection in the rhinopharynx is judicious selection criteria of the patients: Good velar mobility and velopharyngeal closure better than $50 \%$. The case of Patient No. 16 illustrates the limits of this technique. This patient suffers from progressive degenerating myopathy (with chronic progressive external ophthalmoplegia). At the time of the preoperative evaluation, the mobility of the velum was still preserved, but particularly weak. Postoperatively, velopharyngeal closure was still insufficient, and the subjective and objective assessments did not demonstrate any significant improvement of the rhinolalia, despite a satisfactory fat pad that was visible by nasofibroscopy. For this reason, we consider that the decision for autologous fat injection in the rhinopharynx of patients suffering from myopathy or degenerative motoneurone diseases should be carefully made.

The three patients with cleft palate associated with a VCF syndrome obtained excellent postoperative results and were particularly satisfied. The autologous fat injection, as a minor and outpatient procedure is well suited for young patients who suffer from rhinolalia in their personal and educational development.

Patient No. 5 improved her nasality postoperatively, despite elevated nasalance. A possible explanation is that the patient presented with slight nasal congestion during the preoperative nasometric assessment, which could have underestimated the nasalance. The fact remains that the patient was satisfied with her intervention and her postoperative phonation.

The site of the injection is essential to avoid potential complications and to obtain satisfactory functional results. First, the injections should be given directly into the submucosa, taking care not to inject too deeply. The submucosa is safe, without vital structures, and contains leak connective tissue allowing better compliance than the deeper muscle layer. A deeper injection into the prevertebral muscle layer can be painful and runs the risk of carotid injury or embolism with dramatic consequences. Special attention should be paid during the preoperative nasofibroscopic evaluation for identifying an ectopic carotid course. Remacle et al. [8] indicated the principle site of injection to be the median line and warned against injecting too laterally where the fibrous tunic is less dense because larger quantities are required to attain the same results. Fat resorption over time is an important factor that must be considered and an overinjection by approximately 30\% is advocated [36].

Nasal regurgitation is a possible complication after adenoidectomy or UPPP in case of submucous cleft palate or short velum. In our patients, cohort velopharyngeal autologous fat injection has improved nasal regurgitation in one patient with case of VPI after correction of a cleft soft palate (Patient 5). This patient had a light open rhinolalia (preoperative Borel-Masonny score $2 / 1$, preoperative nasalance $25 \%$ ) but was socially handicapped by a recurrent nasal regurgitation with liquids. After the nasopharyngeal fat injection, the regurgitations became exceptional and the patient was satisfied. Velopharyngeal autologous fat injection may represent a complementary treatment to the velopharyngeal reeducation in case of intermittent nasal regurgitation.

It is interesting to note that seven patients (No. 3, 6, 7, $10,11,14,15)$ had a tendency to improve their phonation and diminish their nasalance value even long after the fat injection. This can be explained by the fact that reduction of the velopharyngeal space by the fat injection allows compensatory mechanisms (contraction of the lateral pharyngeal wall) that were impossible before the intervention.

\section{Conclusion}

Autologous fat injection allows a build up of a "neo-Passavant's pad" that improves hypernasal speech in patients with mild velopharyngeal insufficiency or after a suboptimal velopharyngoplasty. Our study shows satisfactory perceptual improvement of nasality, and acoustic nasometry demonstrates a significant decrease in the postoperative nasalance after this intervention. The procedure is simple, minimally invasive and can be performed as an outpatient procedure with only minor discomfort regarding the donor and operative sites. The ideal patient seems to be one who has mild but continuous air emission during phonation without articulatory difficulties. It is especially efficient in young patients after cleft palate repairs and can be proposed for velocardiofacial patients. The choice of autologous fat as the graft tissue is based on the fact that it is easily obtainable, inexpensive and causes no immunologic or foreignbody reaction. Furthermore, unlike teflon, it will not migrate or cause uncontrollable granulomas. Usually, two injections are necessary to obtain an optimal result. Insufficient results or an eventual failure of the procedure does not preclude later corrective intervention, such as a velopharyngoplasty. The long-term outcome of the results and the resorption of the autologous fat must be further evaluated.

Conflict of interest statement None.

\section{References}

1. Boseley ME, Hartnick CJ (2004) Assessing the outcome of surgery to correct velopharyngeal insufficiency with the pediatric 
voice outcomes survey. Int $\mathbf{J}$ Pediatr Otorhinolaryngol 68(11):1429-1433

2. Gersuny R (1980) The classic reprint. Concerning a subcutaneous prosthesis: Robert Gersuny. (Uber eine subcutane Prothese. Zeitschrift f. Heilkunde Wien u Leipzig 21:199, 1900.). Translated from the German by Miss Rita Euerle. Plast Reconstr Surg 65(4):525-527

3. Eckstein Hv (1922) Hartparaffininjektionen in die hintere Rachenwand bei angeborenen und erworbenen Gaumendefekten. Klin Wochenschr (Berl) 1:1185

4. Bluestone CD, Musgrave RH, McWilliams BJ, Crozier PA (1968) Teflon injection pharyngoplasty. Cleft Palate J 5:19-22

5. Smith JK, McCabe BF (1977) Teflon injection in the nasopharynx to improve velopharyngeal closure. Ann Otol Rhinol Laryngol 86(4 Pt 1):559-563

6. Ward PH, Stoudt R Jr, Goldman R (1967) Improvement of velopharyngeal insufficiency by teflon injection. Trans Am Acad Ophthalmol Otolaryngol 71(6):923-933

7. Brauer RO (1973) Retropharyngeal implantation of silicone gel pillows for velopharyngeal incompetence. Plast Reconstr Surg 51(3):254-262

8. Remacle M, Bertrand B, Eloy P, Marbaix E (1990) The use of injectable collagen to correct velopharyngeal insufficiency. Laryngoscope 100(3):269-274

9. Trigos I, Ysunza A, Gonzalez A, Vazquez MC (1988) Surgical treatment of borderline velopharyngeal insufficiency using homologous cartilage implantation with videonasopharyngoscopic monitoring. Cleft Palate J 25(2):167-170

10. Hynes W (1950) Pharyngoplasty by muscle transplantation. Br J Plast Surg 3(2):128-135

11. Witt PD, O’Daniel TG, Marsh JL, Grames LM, Muntz HR, Pilgram TK (1997) Surgical management of velopharyngeal dysfunction: outcome analysis of autogenous posterior pharyngeal wall augmentation. Plast Reconstr Surg 99(5):1287-1296 discussion 1297-300

12. Gaza WV (1926) Ueber freie Fettgewebstransplantation in den retropharyngealen Raum bei Gaumenspalte. Arch Klin Chir 142:590-599

13. Dejonckere PH, van Wijngaarden HA (2001) Retropharyngeal autologous fat transplantation for congenital short palate: a nasometric assessment of functional results. Ann Otol Rhinol Laryngol 110(2):168-172

14. Borel-Maisonny (1975) L'insuffisance vélaire, point de vue de l'orthophoniste. Reeduc Orthoph 13:61-81

15. Fletcher SG (1976) "Nasalance" vs. listner judgements of nasality. Cleft Palate J 13:31-44

16. Coleman SR (1997) Facial recontouring with lipostructure. Clin Plast Surg 24(2):347-367

17. Baijens L, Speyer R, Linssen M, Ceulen R, Manni JJ (2007) Rejection of injectable silicone "Bioplastique" used for vocal fold augmentation. Eur Arch Otorhinolaryngol 264(5):565-568

18. Rubin HJ (1975) Misadventures with injectable polytef (Teflon). Arch Otolaryngol 101(2):114-116

19. Anderson TD, Sataloff RT (2004) Complications of collagen injection of the vocal fold: report of several unusual cases and review of the literature. J Voice 18(3):392-397
20. Ellis JC, McCaffrey TV, DeSanto LW, Reiman HV (1987) Migration of teflon after vocal cord injection. Otolaryngol Head Neck Surg 96(1):63-66

21. Coleman SR (2001) Structural fat grafts: the ideal filler? Clin Plast Surg 28(1):111-119

22. Billings E Jr, May JW Jr (1989) Historical review and present status of free fat graft autotransplantation in plastic and reconstructive surgery. Plast Reconstr Surg 83(2):368-381

23. Bauer CA, Valentino J, Hoffman HT (1995) Long-term result of vocal cord augmentation with autogenous fat. Ann Otol Rhinol Laryngol 104(11):871-874

24. Kaufman MR, Miller TA, Huang C, Roostaien J, Wasson KL, Ashley RK, Bradley JP (2007) Autologous fat transfer for facial recontouring: is there science behind the art? Plast Reconstr Surg 119(7):2287-2296

25. Rohrich RJ, Sorokin ES, Brown SA (2004) In search of improved fat transfer viability: a quantitative analysis of the role of centrifugation and harvest site. Plast Reconstr Surg 113(1):391-395 (discussion 396-397)

26. Nguyen A, Pasyk KA, Bouvier TN, Hassett CA, Argenta LC (1990) Comparative study of survival of autologous adipose tissue taken and transplanted by different techniques. Plast Reconstr Surg 85(3):378-386 discussion 387-389

27. Karacalar A, Orak I, Kaplan S, Yildirim S (2004) No-touch technique for autologous fat harvesting. Aesthetic Plast Surg 28(3):158-164

28. Fagrell D, Enestrom S, Berggren A, Kniola B (1996) Fat cylinder transplantation: an experimental comparative study of three different kinds of fat transplants. Plast Reconstr Surg 98(1):90-96 discussion 97-98

29. Marques A, Brenda E, Saldiva PH, Amarante MT, Ferreira MC (1994) Autologous fat grafts: a quantitative and morphometric study in rabbits. Scand J Plast Reconstr Surg Hand Surg 28(4):241-247

30. Huss FR, Kratz G (2002) Adipose tissue processed for lipoinjection shows increased cellular survival in vitro when tissue engineering principles are applied. Scand J Plast Reconstr Surg Hand Surg 36(3): 166-171

31. Cook T, Nakra T, Shorr N, Douglas RS (2004) Facial recontouring with autogenous fat. Facial Plast Surg 20(2):145-147

32. Rieck B, Schlaak S (2003) Measurement in vivo of the survival rate in autologous adipocyte transplantation. Plast Reconstr Surg 111(7):2315-2323

33. Har-Shai Y, Lindenbaum ES, Gamliel-Lazarovich A, Beach D, Hirshowitz B (1999) An integrated approach for increasing the survival of autologous fat grafts in the treatment of contour defects. Plast Reconstr Surg 104(4):945-954

34. Eremia S, Newman N (2000) Long-term follow-up after autologous fat grafting: analysis of results from 116 patients followed at least 12 months after receiving the last of a minimum of two treatments. Dermatol Surg 26(12):1150-1158

35. Feinendegen DL, Baumgartner RW, Vuadens P, Schroth G, Mattle HP, Regli F, Tschopp H (1998) Autologous fat injection for soft tissue augmentation in the face: a safe procedure? Aesthetic Plast Surg 22(3):163-167

36. Brandenburg JH, Unger JM, Koschkee D (1996) Vocal cord injection with autogenous fat: a long-term magnetic resonance imaging evaluation. Laryngoscope 106(2 Pt 1):174-180 